\title{
Optimum Conditions for Maximum Power of a Direct Methanol Fuel Cell
}

\author{
Mojtaba Tafaoli-Masoule, ${ }^{1}$ Arian Bahrami, ${ }^{2}$ and Danial Mohammadrezaei ${ }^{2}$ \\ ${ }^{1}$ Fuel Cell Research Technology Group, Department of Mechanical Engineering, Babol University of Technology, \\ Babol 47148-71167, Iran \\ ${ }^{2}$ Department of Mechanical Engineering, University of Tehran, Tehran 14395-515, Iran
}

Correspondence should be addressed to Mojtaba Tafaoli-Masoule; mojtaba.tafaoli@yahoo.com

Received 7 June 2013; Accepted 11 July 2013

Academic Editors: J. K. Chen and J. Clayton

Copyright (C) 2013 Mojtaba Tafaoli-Masoule et al. This is an open access article distributed under the Creative Commons Attribution License, which permits unrestricted use, distribution, and reproduction in any medium, provided the original work is properly cited.

\begin{abstract}
It is well known that anode and cathode pressures and cell temperature are the effective parameters in performance of Direct Methanol Fuel Cell (DMFC). In the present study, the genetic algorithm as one of the most powerful optimization tools is applied to determine operating conditions which result in the maximum power density of a DMFC. A quasi-two-dimensional, isothermal model is presented to determine maximum power of a DMFC. For validation of this model, the results of the model are compared to experimental results and shown to be in good agreement with them.
\end{abstract}

\section{Introduction}

Direct methanol fuel cell is one of the most promising transportable power sources which can be used in mobiles, laptops, and small power generation [1]. DMFC is well known to be influenced by large numbers of parameters such as flow rate, methanol concentration, operating temperatures, and anode and cathode pressures. In order to improve the performance of the DMFC, it is necessary to determine the effects of various parameters on the performance of the fuel cell. Other parameters include (1) type and thickness of membrane, (2) catalyst type, (3) geometrical parameters of the flow field, and (4) the type of the gas diffusion layer. However, while these parameters are very important, they are not operating variables. Therefore, they are not variable during fuel cell use.

The fuel cell performance has been the subject of several research papers. Xu et al. [2] used numerical simulation to establish a relationship between the feed concentration of fuel and power density at a certain current density, and they also identified the optimal feed concentration. Moreover, Wang et al. [3] focused on the effect of cell temperature and oxygen flow rate on cell response using the experimental setup.

The main important parameters which affect the performance of the DMFC are operating parameters such as operating temperature and pressure in both sides of the cathode and anode. More recent research has focused on the values of these parameters as derived by experimental approaches, but, in current research, these parameters are optimized using genetic algorithm (GA) and a DMFC analytical model for creating the maximum power as the fitness function of the GA [4].

\section{Genetic Algorithm}

Genetic algorithm is an artificial system and it is similar to human genetic system. GA is a parallel mathematical algorithm that transforms a set of population (namely, chains of chromosomes using genetic operations) into a new population (namely, a next generation) based on the fitness of each chromosome $[4,5]$.

The basic concepts of a genetic algorithm can be conveniently described as follows.

(i) First generation: the first generation is created randomly at definite domain. The size of population is based on the number of variables.

(ii) Evaluation of each solution: each solution or chromosome is evaluated using fitness function. 
(iii) Tournament selection: each of both cases is selected randomly and according to the fitness function, the most appropriate one is introduced into the mating pool.

(iv) Crossover: for the purpose of searching for the best solutions at definite domain, each of both cases is combined with a definitive probability. In the present work, the algorithm uses the real digits systems, and the crossover is defined according to the following relation in which $R$ is a random number between 0 and 1:

$$
\text { child }_{1,2}=\left(\frac{\text { parent }_{1}+\text { parent }_{2}}{2}\right) \pm \mid \text { parent }_{1}+\text { parent }_{2} \mid \times R \text {. }
$$

(v) Mutation: for finding the absolute maximum value and escaping from the local maximum value, mutation is applied with certain probability [4]. The following relation is used for this operator:

$$
\text { child }=\left(\frac{\text { parent }+(1 / n) \sum_{i=1}^{n} \text { parent }_{i}}{2}\right) .
$$

A modified genetic algorithm with an elitist concept is used to ensure that the preferential part in each population is not missing the best solutions. This genetic algorithm code is written in MATLAB software. The selected values of the various parameters of the genetic algorithm are presented in Table 1 while the upper and lower limits of the optimized parameters are shown in Table 2. The flowchart of the genetic code used to obtain the optimal parameters is shown in Figure 1.

The trend of this flow chart can be summarized as follows.

(i) The first step is to begin with random generation of an initial population.

(ii) The analytical model is applied, and the maximum power density as the fitness function of GA is calculated for each chromosome.

(iii) The best chromosome in each generation passes directly to the next generation as an elite chromosome (elitist concept).

(iv) This is followed by selection between each two random chromosomes with elimination of the weak chromosome and preservation of the powerful chromosome.

(v) The crossover and mutation are then applied for further searches. These two important parameters have a controllable role in genetic codes.

(vi) If the condition (i.e., number of generations) is satisfactory, the elite chromosome is shown as the best value of the parameters; otherwise random chromosomes are created in lieu of the eliminated cases following the search program.
TABLE 1: Values of genetic algorithm parameters.

\begin{tabular}{lc}
\hline Number of generations & 200 \\
Population size & 20 \\
Number of parameters & 3 \\
Crossover rate & $95 \%$ \\
Mutation rate & $5 \%$ \\
\hline
\end{tabular}

TABLE 2: Upper and lower values of the parameters to be optimized (search space).

\begin{tabular}{lcc}
\hline Parameter & Lower limit & Upper limit \\
\hline Cathode pressure & $0.5 \mathrm{bar}$ & $3 \mathrm{bar}$ \\
Anode pressure & $0.5 \mathrm{bar}$ & $2.5 \mathrm{bar}$ \\
Cell temperature & $50^{\circ} \mathrm{C}$ & $90^{\circ} \mathrm{C}$ \\
\hline
\end{tabular}

\section{Fitness Function of Genetic Algorithm}

The predominant part of the genetic algorithm is the fitness function as gauged by the chromosomes.

The fitness function-as defined for the present workis the maximum power density, and the goal of this work is to find the best values of the parameters which result in the highest output power.

For the fitness function calculation, calculation of more than one thousand cases is necessary. Unfortunately, large numbers of experiments are needed, which is very time consuming and costly. To overcome this challenge, the DMFC is modeled and used as the fitness function of GA.

3.1. DMFC Modeling. Generally, numerical techniques for solving governing equations of DMFC are very accurate, but they need much more time than other methods. Analytical methods are less accurate and more rapid. For optimization of operating parameters with genetic algorithm, a fast and accurate model is needed. The present work uses a novel technique by combining some techniques from the literature to estimate the behavior of DMFC. For simulating the flow behavior in channels and Membrane Electrode Assembly (MEA), two one-dimensional models are used to solve the governing equations in the direction of channels to calculate concentration, velocity, and pressure distribution and also to solve the equations in the direction normal to the channel to find fuel cell polarization curve [4].

3.2. Mathematical Modeling. Methanol from anode's channel is transferred to MEA by diffusion phenomena, and then, in anode catalyst layer by an electrochemical reaction, proton, water, carbon dioxide, and electron are produced. In cathode catalyst layer, oxygen from cathode channel reacts with proton and electron.

For modeling the fuel cell, two separated regions are considered: one-dimensional flow through the channels and one-dimensional flow across the polymer membrane. Also, MEA is subdivided into three parts: gas diffusion layer, catalyst layer, and membrane.

3.2.1. Channel's Equations. Variations in velocity and concentration through the channel are assumed to be one 


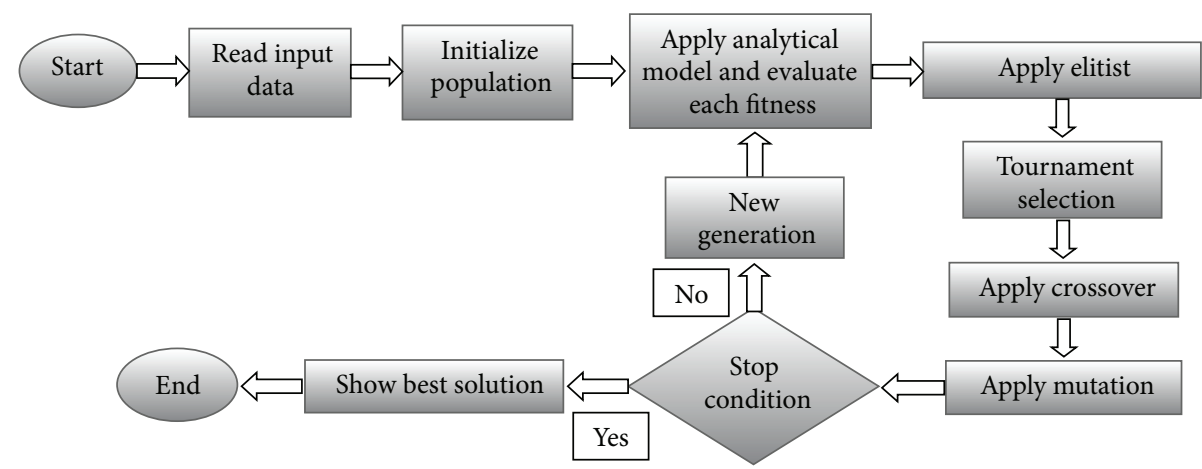

FIGURE 1: The trend of genetic code to obtain the fuel cell optimal parameters.

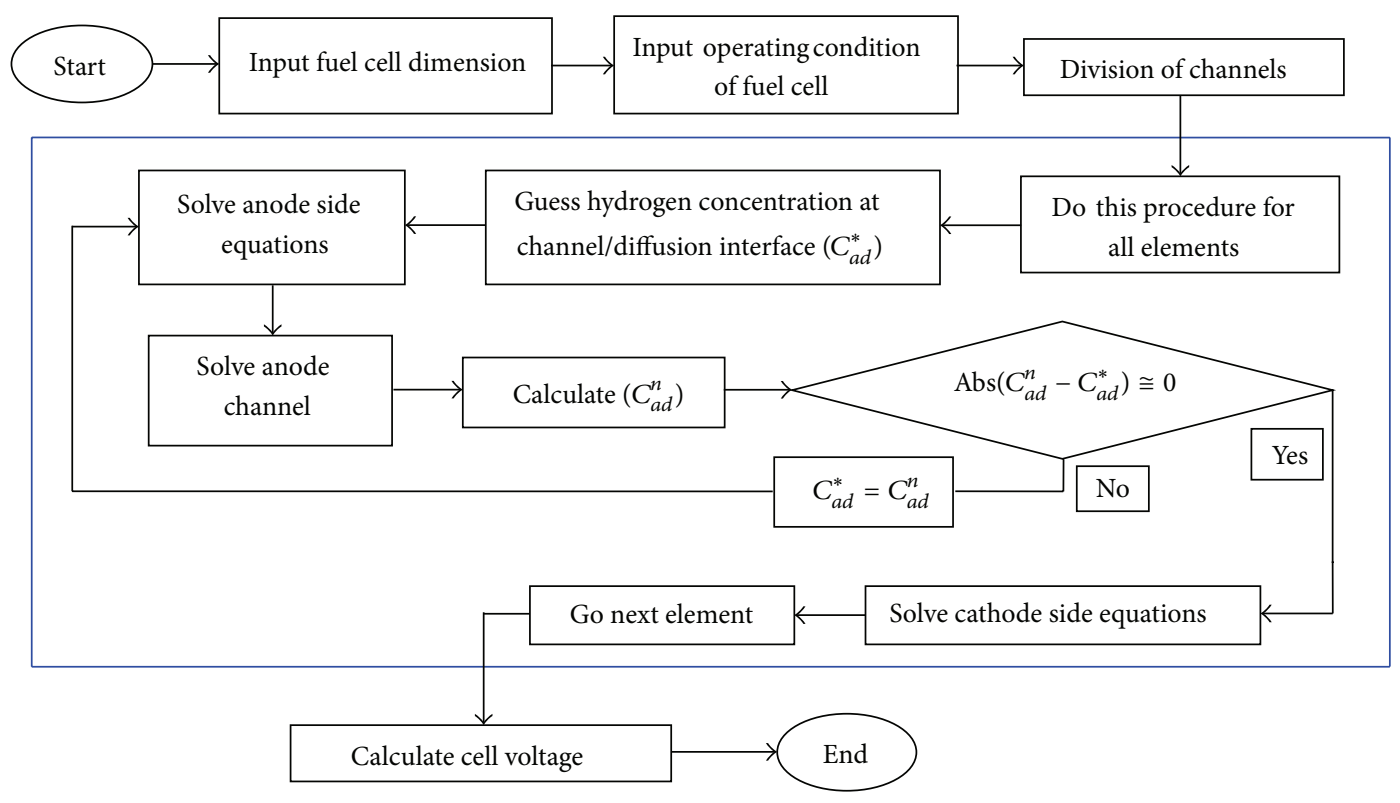

FIGURE 2: Analytic solution algorithm for the DMFC.

dimensional, and so for the single phase flow the equation is

$$
\frac{d}{d x}\left[\rho_{i} U_{i}\right]=-\frac{M_{i} N_{i}}{H}
$$

where $U$ is the average velocity in the channel, $N$ is the molar flux between the channel and MEA, and $H$ and $\rho$ are the channel's height and fluid density, respectively. Subscript $i$ shows gas and liquid phases in cathode and anode channels. By the conservation of species, equation of single-phase flow for each component is [4]

$$
\frac{d}{d x}\left[U_{i} C_{i}^{k}\right]=-\frac{h_{m}^{k}\left(C_{i}^{k}-\left.C_{i}^{k}\right|_{H_{\mathrm{ch}}}\right)}{H},
$$

where $C$ is molar concentration and $k$ is an identifier for the type of species in each side (water and methanol at anode and oxygen and water vapor at cathode side). The right-hand side of (4) shows the effect of diffusion at channel/Gas Diffusion Layer (GDL) interface. Coefficient $h_{m}$ can be estimated by [7]

$$
h_{m}^{k}=\operatorname{Sh} \frac{D_{\mathrm{eff}}^{k}}{H}
$$

where $H$ is the channel's height and Sh is the Sherwood number; $D_{\text {eff }}^{k}$ is effective diffusion coefficient of fluid from channel to gas diffusion layer.

3.2.2. Polymer Electrolyte Membrane (PEM) Modeling. Among the various models published until now, Garcia's model [8] as an analytical model is well known. The model is made based on some simplified assumptions which will be described in the following sections.

Anode. By using the above assumptions and suitable boundary conditions for three domains, gas diffusion layer, catalyst layer, and the membrane, analytic relations for concentration distribution of methanol through them can be derived [8]: 


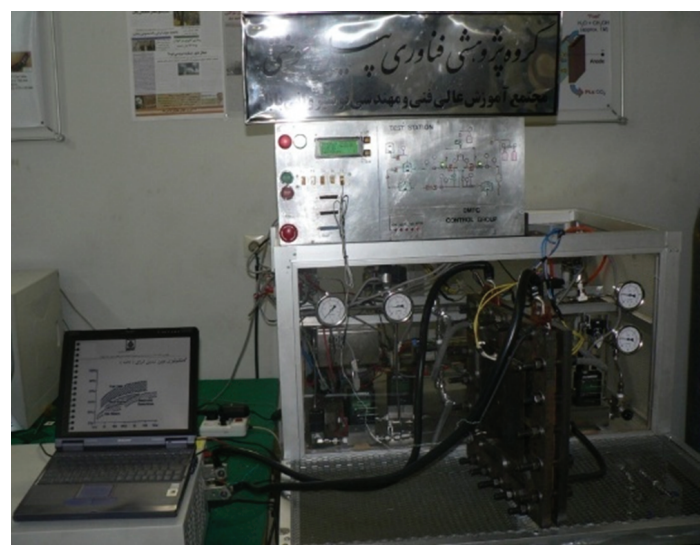

FIGURE 3: Experimental setup of DMFC.

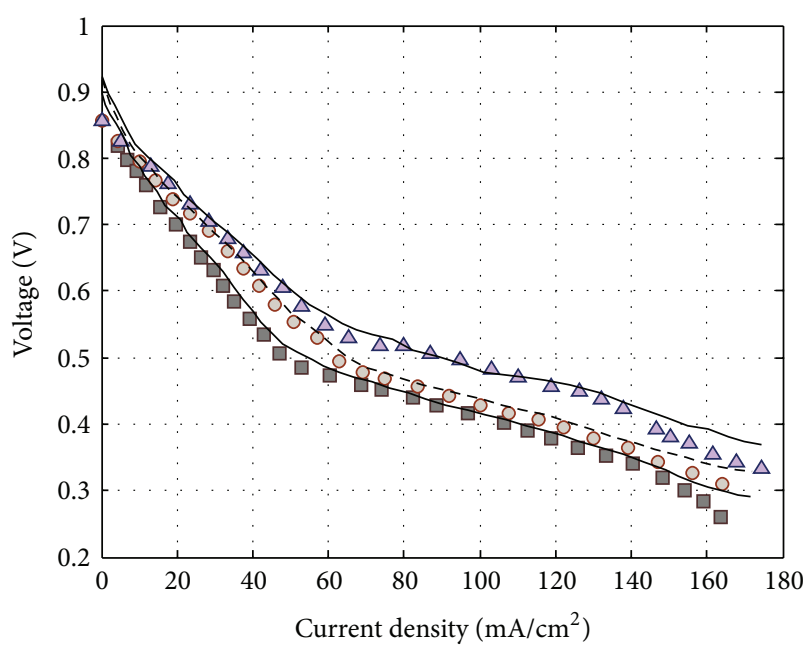

口 Experimental $T=60 \quad$ Modeling $T=60$

○ Experimental $T=70 \quad--$ Modeling $T=70$

$\triangle$ Experimental $T=80 \quad-$ Modeling $T=80$

FIGURE 4: Validation of result by experimental data at constant pressure of 1 bar.

in the diffusion layer:

$$
c_{\mathrm{MeOH}}^{B}=\frac{K_{I} C_{I}^{A}-c_{b}}{\delta_{B}}+c_{b}
$$

in the membrane:

$$
c_{\mathrm{MeOH}}^{M}=K_{I I} c_{I I}^{A}\left(\frac{\delta_{B}+\delta_{A}-Z}{\delta_{M}}+1\right),
$$

in the catalyst layer:

$$
c_{\mathrm{MeOH}}^{A}=\frac{I_{\mathrm{Cell}}}{12 F \delta_{A} D_{A}} Z^{2}+C_{1} Z+C_{2}
$$

where

$$
\begin{gathered}
C_{1}=\frac{c_{I I}^{A}-c_{I}^{A}}{\delta_{A}}-\frac{I_{\text {Cell }}\left(2 \delta_{B}+\delta_{A}\right)}{12 F \delta_{A} D_{A}}, \\
C_{2}=c_{I}^{A}-\frac{\left(c_{I I}^{A}-c_{I}^{A}\right) \delta_{B}}{\delta_{A}}+\frac{I_{\mathrm{Cell}} \delta_{B}\left(\delta_{B}+\delta_{A}\right)}{12 F \delta_{A} D_{A}} .
\end{gathered}
$$

Thus, the current density can be calculated by

$$
I_{\mathrm{Cell}}=\int_{\delta_{B}}^{\delta_{B}+\delta_{A}} a I_{0, \mathrm{ref}}^{\mathrm{MeOH}} \frac{k c_{\mathrm{MeOH}}^{A}}{c_{\mathrm{MeOH}}^{A}+\lambda e^{\alpha_{A} \eta_{A} F / R T}} e^{\alpha_{A} \eta_{A} F / R T} d z,
$$

where $\delta_{A}$ and $\delta_{B}$ are catalyst and backing layers thicknesses, respectively, and $I_{0, \text { ref }}$ is the reference current density. Here $a, \alpha_{A}, \eta_{a}, F$, and $T$ are the specific surface area of the anode, anode activation, anode over potential, faraday constant, and cell temperature, respectively. From the above, the methanol crossover through membrane can be estimated as

$$
N_{\mathrm{MeOH}}^{M}=-D_{M} \frac{d c_{\mathrm{MeOH}}^{M}}{d Z}+\xi_{\mathrm{MeOH}} \frac{I_{\mathrm{Cell}}}{F} .
$$

In the right-hand side, the first term and the second term show the methanol crossover due to diffusion from membrane and the crossover by electroosmotic drag, respectively. Table 3 shows the values of parameters used.

Cathode. Assuming single-phase flow, the continuity equation leads to

$$
d(\rho u)=0
$$

Thus, the mass flow rate per unit area is

$$
\rho u=\text { constant. }
$$

From Darcy's equation,

$$
\nabla p=-\frac{\mu}{k} u
$$

where $k$ and $\mu$ are permeability of cathode gas diffusion layer and viscosity of gas, respectively. The distribution of species at cathode side (oxygen, water vapor, and carbon dioxide) can be estimated by Maxwell's equation of distribution as

$$
\nabla x_{i}=\sum_{j} \frac{x_{i} N_{j}-x_{j} N_{i}}{C_{T} D_{i j}^{\mathrm{eff}}},
$$

where $x$ and $N$ are the mole fraction and molar flow rate of each species, respectively, and $D_{i j}$ is the diffusion coefficient [4]. By solving (6) to (15), velocity and mole fraction of gases in cathode GDL can be obtained.

3.3. Methodology of Solution. The modeling in this paper is based on two one-dimensional models linked together. Since for calculating current density, $I_{\text {cell }}$, at a certain anode over potential, $\eta_{a}$, Garcia's model [8] needs concentration of methanol at interface of the channel and GDL, so it can 
TABLE 3: Values of fuel cell parameters.

\begin{tabular}{|c|c|c|c|c|}
\hline Parameter & Symbol & Unit & Value & Reference \\
\hline Diffusion coefficient of methanol in liquid & $D_{m}$ & $\mathrm{~cm}^{2} \mathrm{~s}^{-1}$ & $4.9 \times 10^{-6} e^{2436(1 / 333-1 / T)}$ & {$[6]$} \\
\hline Diffusion coefficient of methanol in membrane & $D_{B}$ & $\mathrm{~cm}^{2} \mathrm{~s}^{-1}$ & $2.8 \times 10^{-5} e^{2436(1 / 353-1 / T)}$ & [6] \\
\hline Diffusion coefficient of oxygen & - & $\mathrm{cm}^{2} \mathrm{~s}^{-1}$ & $1 \times 10^{-3}$ & [7] \\
\hline Reference current density of methanol & $I_{0, \mathrm{ref}}^{\mathrm{MeOH}}$ & $\mathrm{A} \mathrm{cm}^{-2}$ & $94.25 \times 10^{-4} e^{35570(1 / 353-1 / T)}$ & [7] \\
\hline Reference current density of oxygen & $I_{0, \text { ref }}^{\mathrm{O}_{2}}$ & $\mathrm{~A} \mathrm{~cm}^{-2}$ & $0.04222 \times 10^{-4} e^{73200(1 / 353-1 / T)}$ & [7] \\
\hline
\end{tabular}

TABLE 4: Values of DMFC parameters.

\begin{tabular}{lcc}
\hline Parameter & Unit & Value \\
\hline Number of cells in stack & - & 1 \\
Anode and cathode width of channel & $\mathrm{cm}$ & 0.1 \\
Anode and cathode height of channel & $\mathrm{cm}$ & 0.1 \\
Active area & $\mathrm{cm}^{2}$ & 625 \\
Total area & $\mathrm{cm}^{2}$ & 900 \\
Anode and cathode flow pattern & - & Serpentine \\
Anode loading & $\mathrm{mg} / \mathrm{cm}^{2}$ & 4.0 \\
Cathode loading & $\mathrm{Pt}-\mathrm{Ru}$ & \\
Methanol concentration at anode & $\mathrm{mg} / \mathrm{cm}^{2} \mathrm{Pt}$ & 4.0 \\
inlet & $\mathrm{Molar}$ & 1 \\
CH ${ }_{3} \mathrm{OH}$ & $\mathrm{mL} / \mathrm{min}^{2}$ & 30 \\
Air & $\mathrm{SL} / \mathrm{min}^{2}$ & 2.5 \\
Cell pressure & Bar & 1.0 \\
Type of MEA & - & Nafion 117 \\
\hline
\end{tabular}

TABLE 5: Constant parameters of model.

\begin{tabular}{lcc}
\hline Condition and parameters in use & Value & Reference \\
\hline $\begin{array}{l}\text { Anode and cathode diffusion layer } \\
\text { thicknesses }(\mathrm{cm})\end{array}$ & 0.03 & {$[5,6]$} \\
Anode catalyst layer thickness $(\mathrm{cm})$ & 0.005 & {$[6]$} \\
Cathode catalyst layer thickness $(\mathrm{cm})$ & 0.003 & {$[6]$} \\
Anode and cathode diffusion layer porosity & 0.7 & {$[7]$} \\
Anode and cathode catalyst layer porosity & 0.3 & - \\
Anodic transfer coefficient $\left(\alpha_{\mathrm{a}}\right)$ & 0.8 & {$[6]$} \\
Cathodic transfer coefficient $\left(\alpha_{\mathrm{c}}\right)$ & 0.8 & {$[6]$} \\
Membrane layer thickness $(\mathrm{cm})$ & 0.02 & {$[6]$} \\
MEA ionic conductivity $(\mathrm{S} / \mathrm{cm})$ & 0.036 & {$[8]$} \\
MEA porosity & 0.3 & {$[7]$} \\
\hline
\end{tabular}

be a suitable parameter for making connection between the channel and PEM.

After dividing the two solution domains (channels and PEM), a guessed anode's channel and GDL interface concentration $\left(C_{\mathrm{MeOH}}\right)$ are used for solving Garcia's model at anode side to estimate the resulted current density, methanol consumption, and crossover. Then, the net penetration of each species in PEM from channel $\left(N_{i}\right)$ is clear. The oxygen consumption at cathode side can also be obtained by solving (12) to (15). Then, by using (3) to (6), input velocity and concentration of methanol for next cell can be estimated and $C_{\mathrm{MeOH}}$ can be updated by (4). After some number of iterations and reaching a suitable solution error, the next step is started. By following this process, $I_{\text {cell }}$ and then cell voltage can be estimated. The flow chart of this procedure is shown in Figure 2 which gives an overview of the solution procedure.

3.4. Validation of Modeling. For this purpose, an experimental setup for direct methanol fuel cell was developed (Figure 3) using different values for the experimental parameters (Table 4). The initial constant values for fuel cell modeling are different in research papers. These fuel cell constant values for simulation and optimization are shown in Table 5. In Figure 4, the polarization curves of the model and experimental results in different cell temperatures are compared. As shown in Figure 4, the analytic polarization curves are in good agreement with experimental curves, but they are not exactly the same as experimental curves due to some simplified assumptions for developing the analytical model. For instance, the current of DMFC was assumed to be one dimensional. So the proposed curves have a little difference compared with their corresponding experimental curves especially at the end of curves due to concentration losses. Although this method for creating fitness function values is not very precise and other approaches such as CFD method have an accurate response, the proposed analytical model is very useful and has the capability to merge with genetic code while other approaches are time consuming and costly and it is not possible to apply them especially at numerous numbers of GA's generations. Therefore, analytical approaches which have fast and acceptable responses are very suitable.

By comparing the presented analytical model with experimental results, the proposed model is validated. The proposed analytical model also has the ability to be used in the calculation for fitness function of genetic algorithm. Since the results of parallel channels modeling are in good agreement with experimental approach, this type of channels was assumed for optimization.

\section{Optimization Result and Discussion}

By executing this MATLAB optimization code, solutions are generated for maximum power densities (Table 6). The obtained values for parameters create the maximum power density of $567 \mathrm{mw} / \mathrm{cm}^{2}$. The convergence of the genetic algorithm towards the best solution is also illustrated in Figure 5. The higher cell temperature gives better fuel cell performance. Increasing the cell temperature can invigorate the activity of the catalysts and can increase the mass transfer of reactants. 
TABLE 6: Optimal values for parameters.

\begin{tabular}{lc}
\hline Cell temperature $\left({ }^{\circ} \mathrm{C}\right)$ & 90 \\
Anode pressure (bar) & 2.5 \\
Cathode pressure (bar) & 3 \\
\hline
\end{tabular}

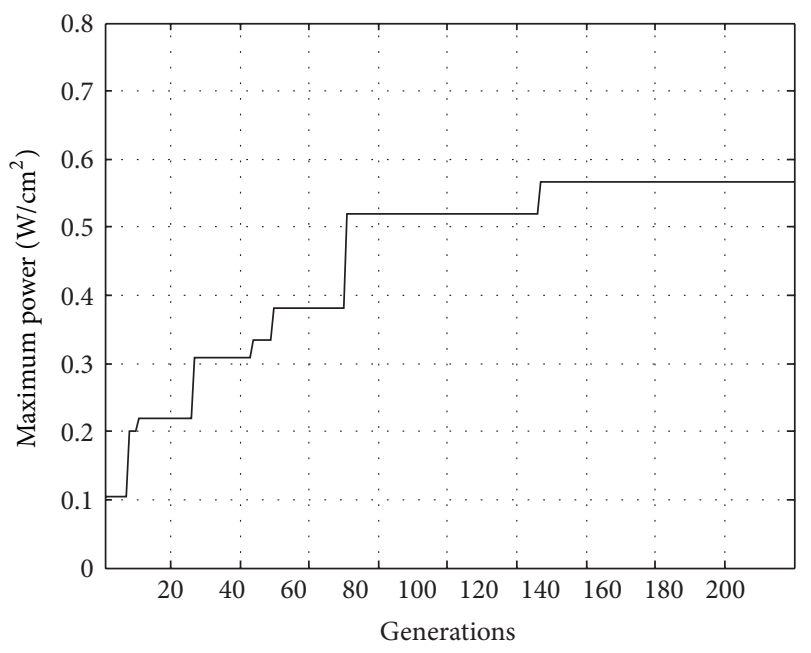

FIgURE 5: Maximum fitness during the generations.

It also results in better proton transportation through the Nafion membrane and much faster mass transfer processes inside the cell. The cell performance in either anode's or cathode's side would be improved, and it can be justified as mentioned in the following.

(i) The cell pressure increase would lead to an increase in cell reactants' pressure.

(ii) In regard to the pressure increase, the activated gases permeability in the gas diffusion layer would be increased, besides; the mass transfer resistance of cell would be decreased.

(iii) The gases are stagnant in the extensive areas on GDL corners and current distribution channels when the cell is working under the environmental pressure. These areas in MEA usually do not produce any current, but when the cell is working under the pressure, the reactants are forced to pass these areas; therefore, the effective active area in the electrochemical reactions would be increased.

Unfortunately the present experimental setup cannot tolerate the obtained optimum loading condition of the test due to incapability of the structure to pass this temperature condition, but this optimum value for producing maximum power density is closely in good agreement with [9].

\section{Conclusions}

In this study, the genetic algorithm was applied to determine the optimal parameters for maximum power of a monocell Direct Methanol Fuel Cell. A quasi-two-dimensional (1D1D), isothermal model was presented for the DMFC. For validation of the model, the result of the model was compared to experimental data and the literature and shown to be in in good agreement with them. This model was used for determining the maximum power density of a DMFC which was considered as the fitness function for GA. A genetic code was developed using MATLAB. Finally, optimal values for DMFC's cell temperature and anode and cathode pressures were obtained: $90^{\circ} \mathrm{C}$ and 2.5 and 3 bars, respectively.

\section{References}

[1] D. Kareemulla and S. Jayanti, "Comprehensive one-dimensional, semi-analytical, mathematical model for liquid-feed polymer electrolyte membrane direct methanol fuel cells," Journal of Power Sources, vol. 188, no. 2, pp. 367-378, 2009.

[2] C. Xu, P. M. Follmann, L. T. Biegler, and M. S. Jhon, "Numerical simulation and optimization of a direct methanol fuel cell," Computers and Chemical Engineering, vol. 29, no. 8, pp. 18491860, 2005.

[3] M. Wang, H. Guo, and C. Ma, "Dynamic characteristics of a direct methanol fuel cell," Journal of Fuel Cell Science and Technology, vol. 3, no. 2, pp. 202-207, 2006.

[4] M. Tafaoli-Masoule, M. Shakeri, H. Nemati, and M. Safari, "Application of genetic algorithm to both sides pressure optimization of PEMFC," in Proceedings of the 13th International Multitopic Conference (INMIC '09), pp. 1-6, Islamabad, Pakistan, December 2009.

[5] C. Martín-Del-Campo, J. L. François, L. Avendaño, and M. González, "Development of a BWR loading pattern design system based on modified genetic algorithms and knowledge," Annals of Nuclear Energy, vol. 31, no. 16, pp. 1901-1911, 2004.

[6] H. Guo and C. Ma, "2D analytical model of a direct methanol fuel cell," Electrochemistry Communications, vol. 6, no. 3, pp. 306-312, 2004.

[7] Z. H. Wang and C. Y. Wang, "Mathematical modeling of liquidfeed direct methanol fuel cells," Journal of the Electrochemical Society, vol. 150, no. 4, pp. A508-A519, 2003.

[8] B. L. Garca, V. A. Sethuraman, J. W. Weidner, R. E. White, and R. Dougal, "Mathematical model of a direct methanol fuel cell," ASME Journal of Fuel Cell Science and Technology, vol. 1, no. 1, pp. 43-48, 2004.

[9] R. W. Reeve, Update on Status of Direct Methanol Fuel Cells, Gosport, London, UK, 2002. 

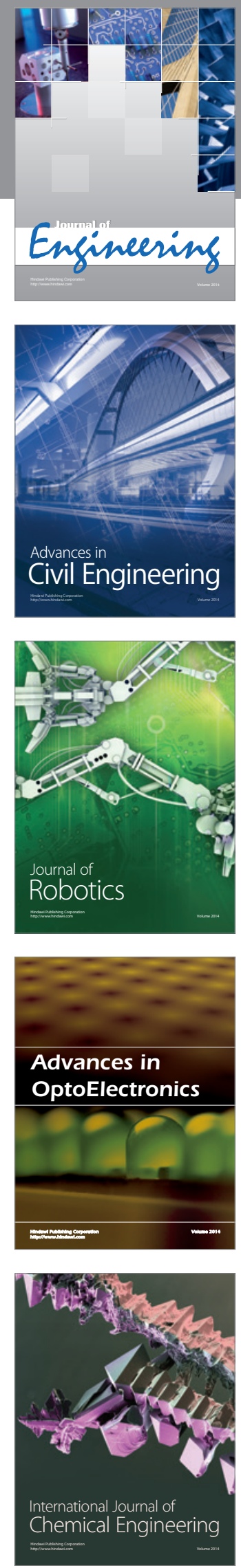

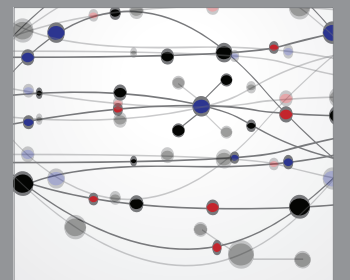

The Scientific World Journal
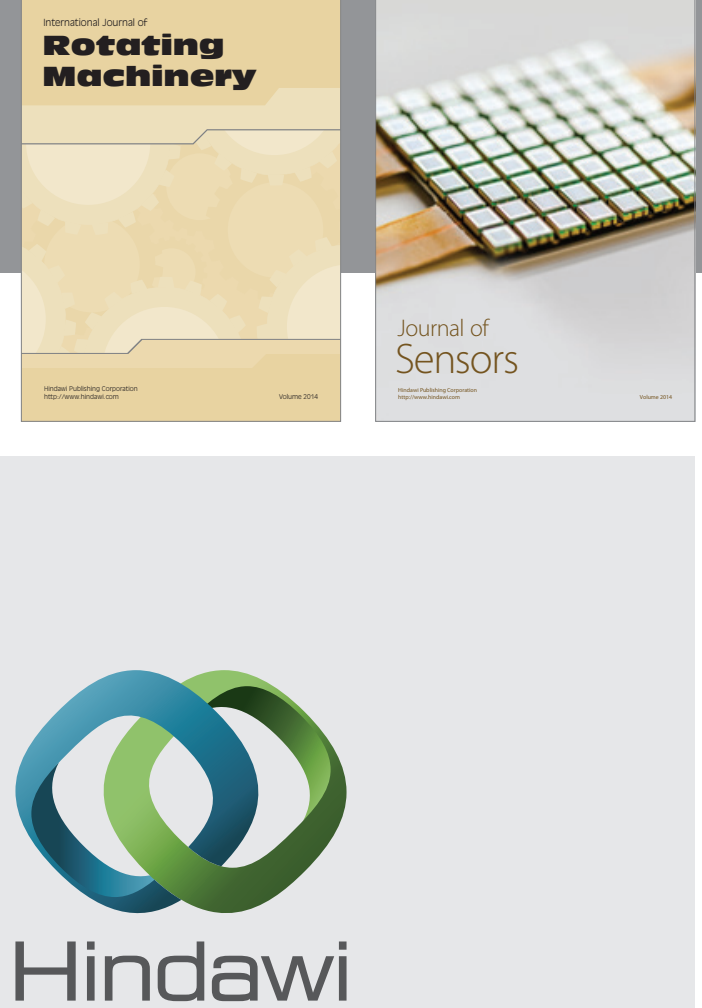

Submit your manuscripts at http://www.hindawi.com
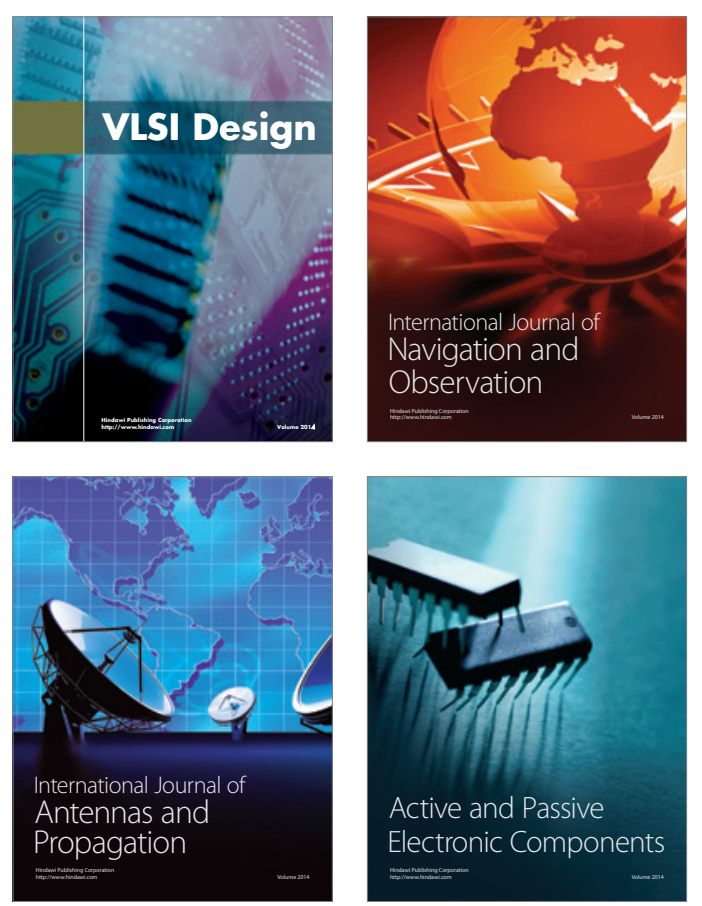
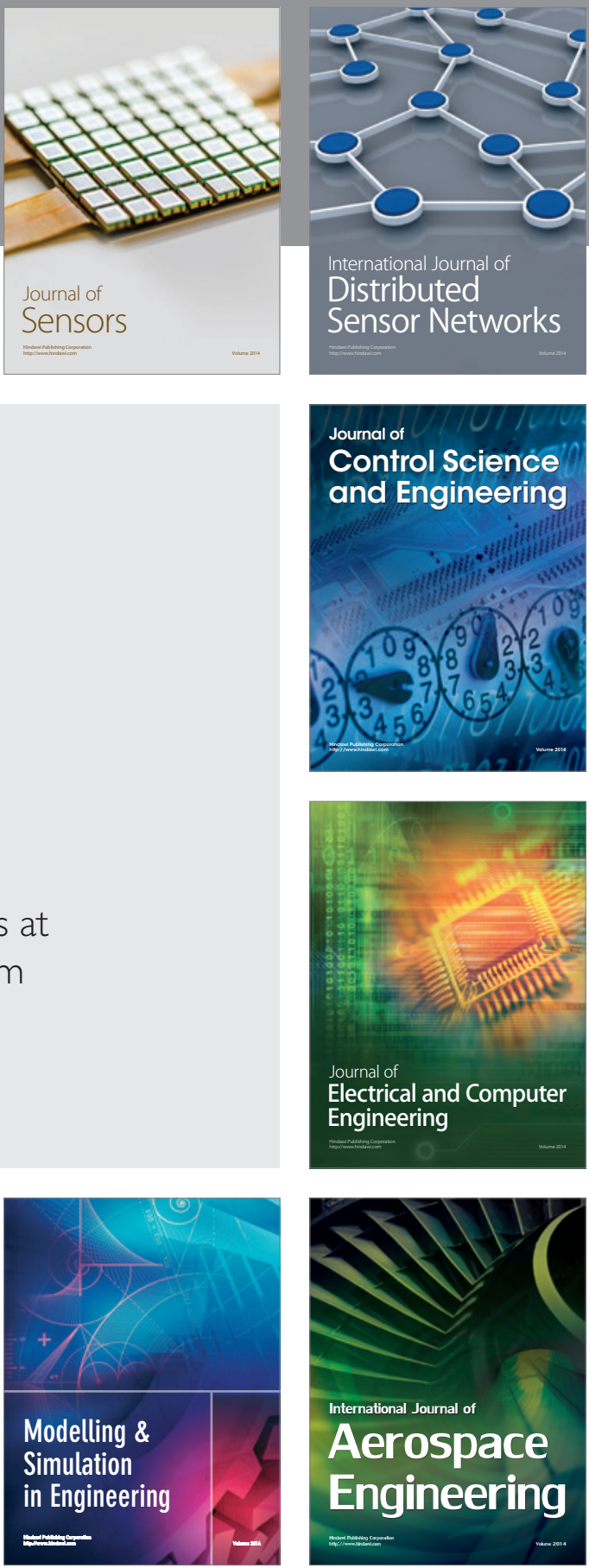

Journal of

Control Science

and Engineering
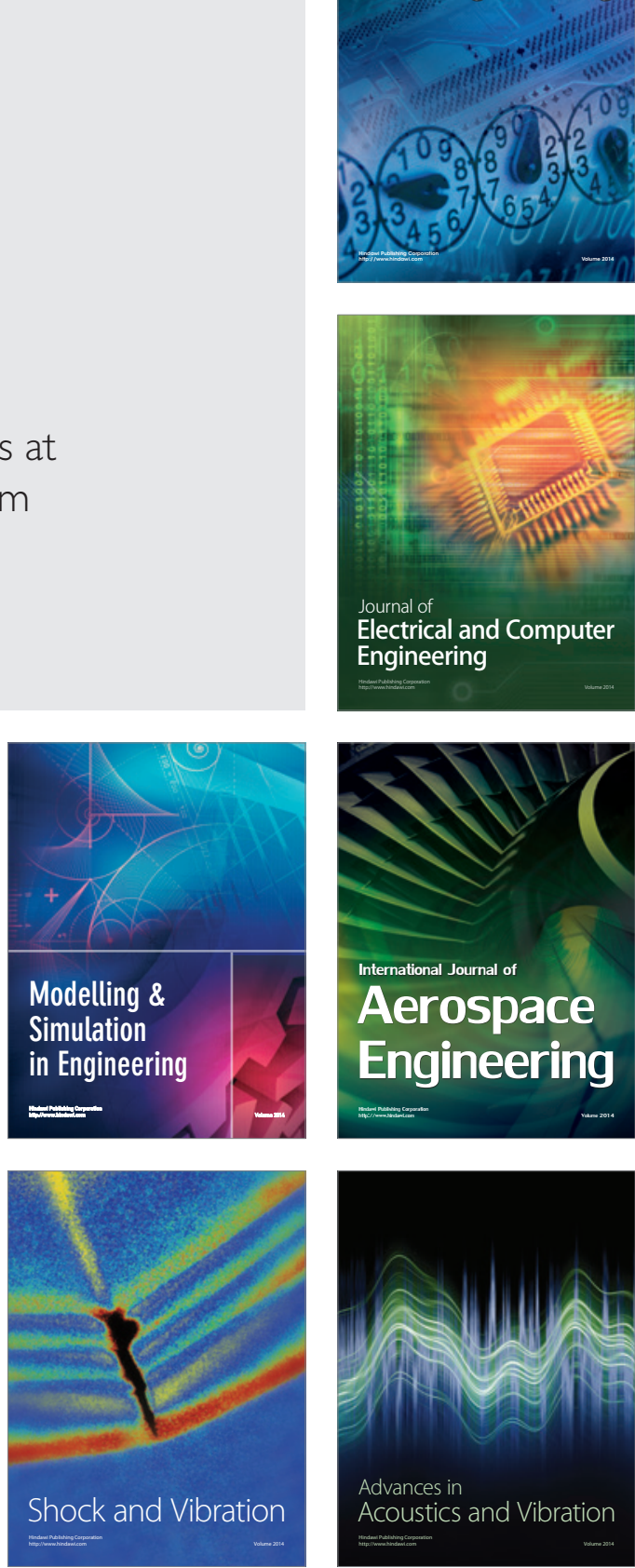